\title{
LXXX. Case of retention of urine successfully treated by puncturing the bladder
}

\author{
John Taunton Esq.
}

To cite this article: John Taunton Esq. (1814) LXXX. Case of retention of urine successfully treated by puncturing the bladder, Philosophical Magazine Series 1, 43:193, 369-370, DOI: $10.1080 / 14786441408638048$

To link to this article: http://dx.doi.org/10.1080/14786441408638048

里 Published online: 27 Jul 2009.

Submit your article to this journal $₫$

Џ Article views: 2

Q View related articles 5 
nfter recovering from a death-like insensibility, were painful and eppressive for many days.

I am your obedient servant,

To Messrs. Nicholson and Tilloch.

SameEL WrtTer.

LXXX. Case of Retention of Urine successfully treated by puncturing the Bladder. By JoHn Taunton, Esq., Surgeon to the City and Finslury Dispensaries, and to the City of London Truss Society for the Relief of the ruptured Poor, \&ic. \&oc.

SIRs,muscular man, his general health extremely good, with the exception of an ulcerated leg for the last twenty years, and during the last eight or ten hydrocele on one side and hernia on the other. For the last twelve months also he has experienced some difficulty in voiding his urine, which came away in small quantities at a time, and with frequent calls. On July 7,1813 , after a hearty dinner he sat an hour or two in the open air, during which time he was attacked by violent pain in the abdomen, with purging. These symptoms continued all night, and his urine came away in drops without any effort. On the 8th he was admitted a patient of the Finsbury Dispensary.-The abdomen was hard, swelled, and painful; and there was a considerable degree of fever attended with thirst :' the purging also continued. The leg, which had been much inflamed for the last three months, is now better. An anodyne fomentation and some powdered rhubarb were prescribed for him by the physician who visited him till the $13 \mathrm{th}$; and during the interval aperient fomentations, \&c. were resorted to with a view to relieve the complaint in the bowels and general disorder of the constitution. On the 13th Mr. T'aunton was requested to see him, on account of the stillicidium urinæ which had existed from the beginning of the attack. He found him with quick weak pulse, brown tongue, violent pain in the region of the bladder, which was distended, forming a tumour reaching above the umbilicus: the urine was dribbling away involuntarily. The catheter was introduced; but could not be passed beyond the neck of the bladder. The smallest gum catheters were'also tried without effect. Continuata foment.

14th. The bladder reaches still higher up: the catheter again attempted, but in vain; other symptoms the same. Puncturing above the pubis was determined on, and consented to by the patient. Upon going to perform the operation at three o'clock, it was found that a considerable quantity of urine had come away involuntarily and almost in a stream, and the patient Vol. 43. No. 193. May 1814. A a would 
would nut now consent to the operation. Nor was it urged, as the blarider was greatly reduced in size. The tongue was still brown, and the other bad symptoms continued. 15th. The patient was nearly in the same state: stillicidium constant. 16th. The tumour formet by the bladder is more prominent and circumscribed; reaches about two inches above the umbilicus: in other respects the same:-pain decreased. The operation was now performed, and betwcen two and three quarts of urine were taken away; it was not grumous, nor materially altered from that of a healthy person. During the operation the pulse fell, but coon regained its strength. A long elastic catheter was left in the wound, and properly secured. A cordial mixture was prescribed. In the evening the bougie used as a stilette was withdrawn, and the urine evacuated: no pain on pressure on the abdomen, which was soft, and the tongue clean. 18th. The urine escapes by the side of the catheter, but is not effused into the cellular membrane; adhesive inflammation was visible round the wound. The urine flows involuntarily, but he feels easy. He took broth yesterday: the tongue was clean, the pulse was stronger and slower. 19th and $20 \mathrm{th}$. A slight blush of inflammation immediately around the wound: no pain experienced on pressure. 21 st. Has felt pain in the night, seemingly from a temporary obstruction to the flow of urine, which was soon evacuated, and the pain went off. $22 \mathrm{~d}$. The catheter escaped during the night; but the urine flows freely from the orifice, and he continues to gain strength. From this period to August 28th convalescent. The passage of a small bougie has been attempted two or three times without success. 'The patient complains of considerable pain in the urethra, which prevents his sleeping without opiates; and he takes a grain of opium every night. He walks out, and his spiritg afe better. September 10th. The quantity of urime discharged by the urethra has sensibly increased, until it all comes away by that channel. The opening had closed a few days before, but it broke out when straining at stool ; he does not know whether any urine escaped or not, but nothing comes from it at present. $17 \mathrm{th}$. Much in the same state; complains of soreness where the puncture was made, and a little matter oozes from it; a considerable quantity of urine came through on the 13 th and 14 th. From this time he gradually recovered, and was discharged cured the beginning of November, since which he has not had any return of the complaint.

To Messrs. Nicholson and Tilloch.

John Taunton. 